\title{
TRENDS IN MORTALITY RATES
}

$\mathbf{T}$ he health of Australians has improved over the past 20 years. Evidence shows a fall in the all-cause mortality rate and striking reductions in the death rates from ischaemic heart disease, stroke and injury ${ }^{1}$.

Although mortality is an important measure of health status, there have been few co-ordinated efforts in NSW to plot trends in death rates over time. The most significant recent piece of work on mortality in NSW was prepared by Bob Gibberd's group from the Hunter Region?.

However that work concentrated on spatial variations in the major causes of death for 1979-83 rather than on trends over time. The need for a review of time trends in the major causes of mortality stimulated preparation of a report by staff of the Epidemiology Branch of the NSW Health Department.

Data were obtained from the NSW Registry of Births, Deaths and Marriages death record for the years 1971-1987. The analysis was confined to changes in the age- and sex-specific mortality rates for the major causes of death. For this report we present 1) trends in the all-cause death rates and 2) trends in selected cause-specific death rates, some of which have not declined over time.

\section{CRUDE DEATH RATE}

Since 1971 the total number of deaths has remained constant, at around 40,000 a year. This represents a fall in the crude death rate, as there has been an increase in the population of around 1 per cent a year since 1971 . The crude death rate fell by 15 per cent in males (from 9.6/1000 in 1971 to $8.2 / 1000$ in 1987) and 12 per cent in females (8.1/1000 in 1971 to $7.1 / 1000$ in 1987). Similar trends occurred in all age and sex groups.

\section{ISCHAEMIC HEART DISEASE AND STROKE}

The decline in the death rate from ischaemic heart disease (IHD) in Australia began in the mid-1960s and has continued. The analysis of mortality data showed that all of the age- and sex-specific death rates from IHD (ICD-9 410-414) and cerebrovascular disease (CVD) (ICD-9 430-438) had fallen between 1971 and 1987. For example in the 45-64-year age group the death rate from IHD fell by 48 per cent in males and 55 per cent in females, and from CVD by 55 per cent in males and 64 per cent in females over the time period (see Figure 1).

The declining death rate has been linked to changes in lifestyle, most notably improved diet and a reduction in smoking. Despite these great strides, IHD and CVD remain the single most important cause of death in NSW (39 per cent of deaths in 1987).

\section{FIGURE 1}

\section{IHD AND CVD DEATH RATES, 1971-1987}

BY SEX: 45-64 YEARS

600 RATE $/ 100,000$

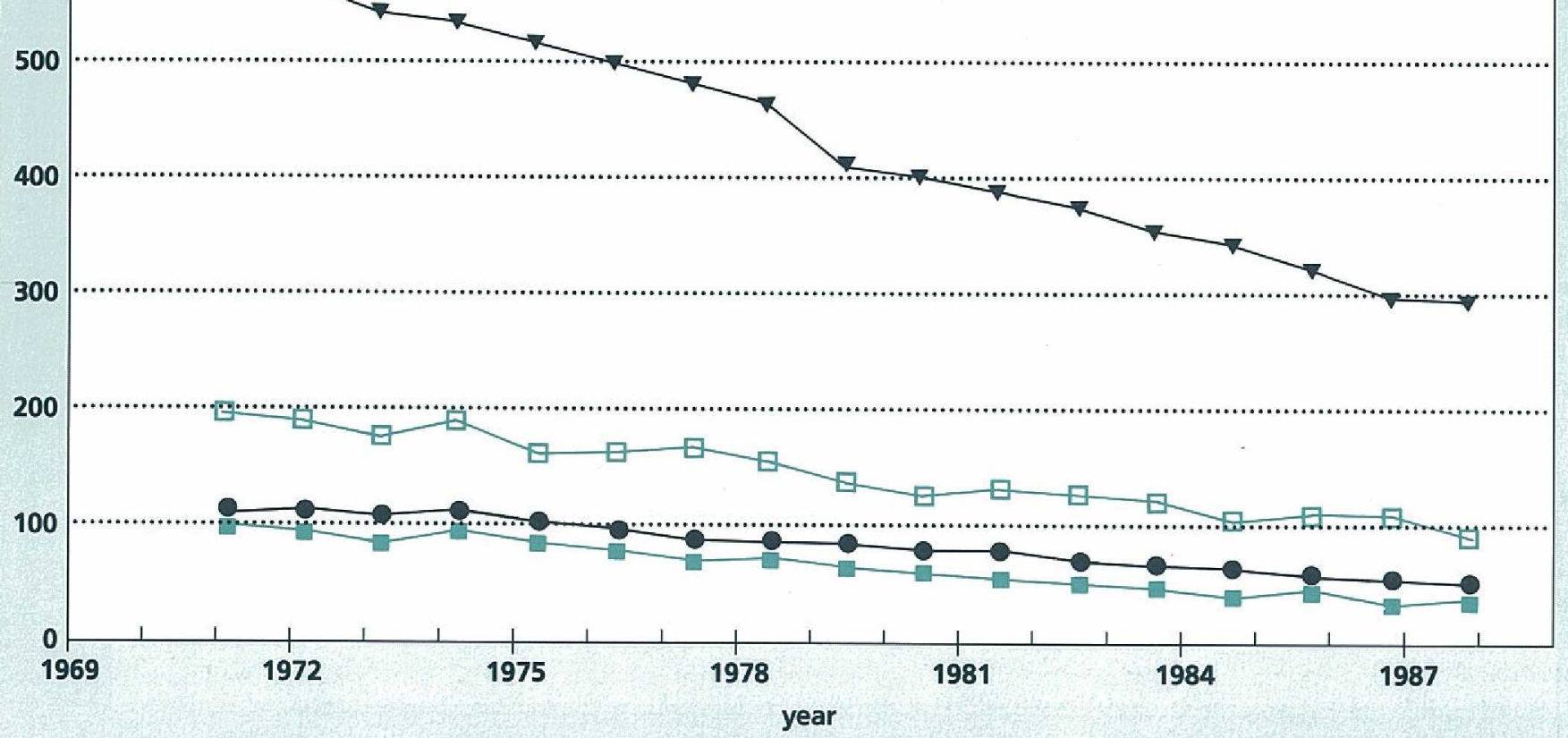

$\longrightarrow$ IHD-male

口 IHD-female

- CVD-male

- CVD-female 


\section{INFANT DEATH RATE}

The fall in the infant death rate since 1971 has been astounding. The number of deaths dropped from 1748 in 1971 to 747 in 1987 despite a relatively stable birth rate. Figure 2 shows that since 1971 the infant death rate has fallen by 55 per cent for males and 44 per cent for females.

Most of the decline occurred in the early and mid-1970s and has continued to a lesser extent since then. Reasons for this are not well understood, although the greatest changes have occurred during the neonatal period.

Of the many specific causes of death in the first year of life, Sudden Infant Death Syndrome (SIDS) (ICD-9798.0) appears to be one of growing importance. SIDS was first recorded as a cause of death in NSW during 1979, after the adoption of the ninth revision of the International Classification of Diseases, Injuries and Causes of Death in NSW.

Against the trend, the death rate from SIDS has increased by 47 per cent for males and 53 per cent for females since 1979 (Figure 3). Reasons for this apparent increase in incidence are not known.

\section{$\square$ LUNG CANCER}

Lung cancer (ICD-9 162) is the leading cause of death from cancer in men and the third commonest cause in women. While death from lung cancer is about four times more common among men than women, the gap is narrowing. In people aged 65 years and older the mortality rate from lung cancer rose between 1971 and 1987, doubling in females and rising to a lesser extent (20 per cent) in males. In the 45-64 age group the sex differences are more pronounced: the death rate for females increased nearly 50 per cent whereas the rate for men remained static (Figure 4). This disparity reflects the changing patterns of smoking.

It is probable that changes in smoking behaviour will continue to influence trends in the lung cancer death rate into the 21 st century. Much of the decline in smoking rates observed during the 1980s has been attributed to the Quit For Life mass media anti-smoking campaign'. Between 1983 and 1987 the prevalence of smoking declined by 6 per cent in men, from 39 per cent to 33 per cent, and 2.6 per cent in women, from 31.6 per cent to 29 per cent ${ }^{3,4}$.

Predictions suggest the mortality rate from lung cancer will begin to fall for men at the end of the century, particularly in the 45-64 age group, as the effects of the NSW anti-smoking campaigns become apparent.

The outlook is not so bright for women smokers who took up the habit in increasing numbers 20-30 years ago and now are moving into the high-risk age groups for lung cancer.

\section{FIGURE 2}

INFANT DEATH, 1971-1987

UNDER 1 YEAR

RATE/100,000

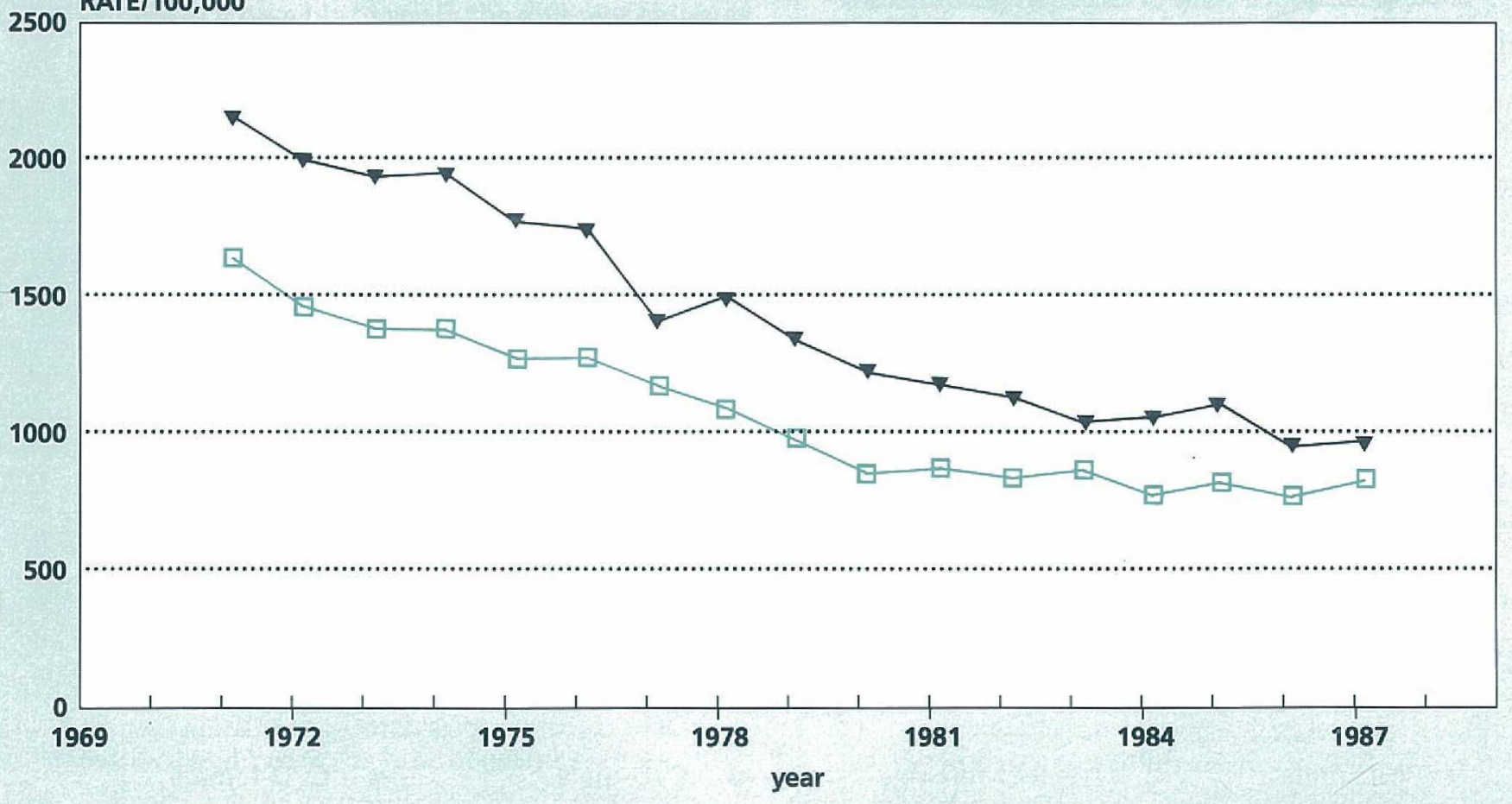




\section{FIGURE 3 \\ SUDDEN INFANT DEATH, 1979-1987}

UNDER 1 YEAR

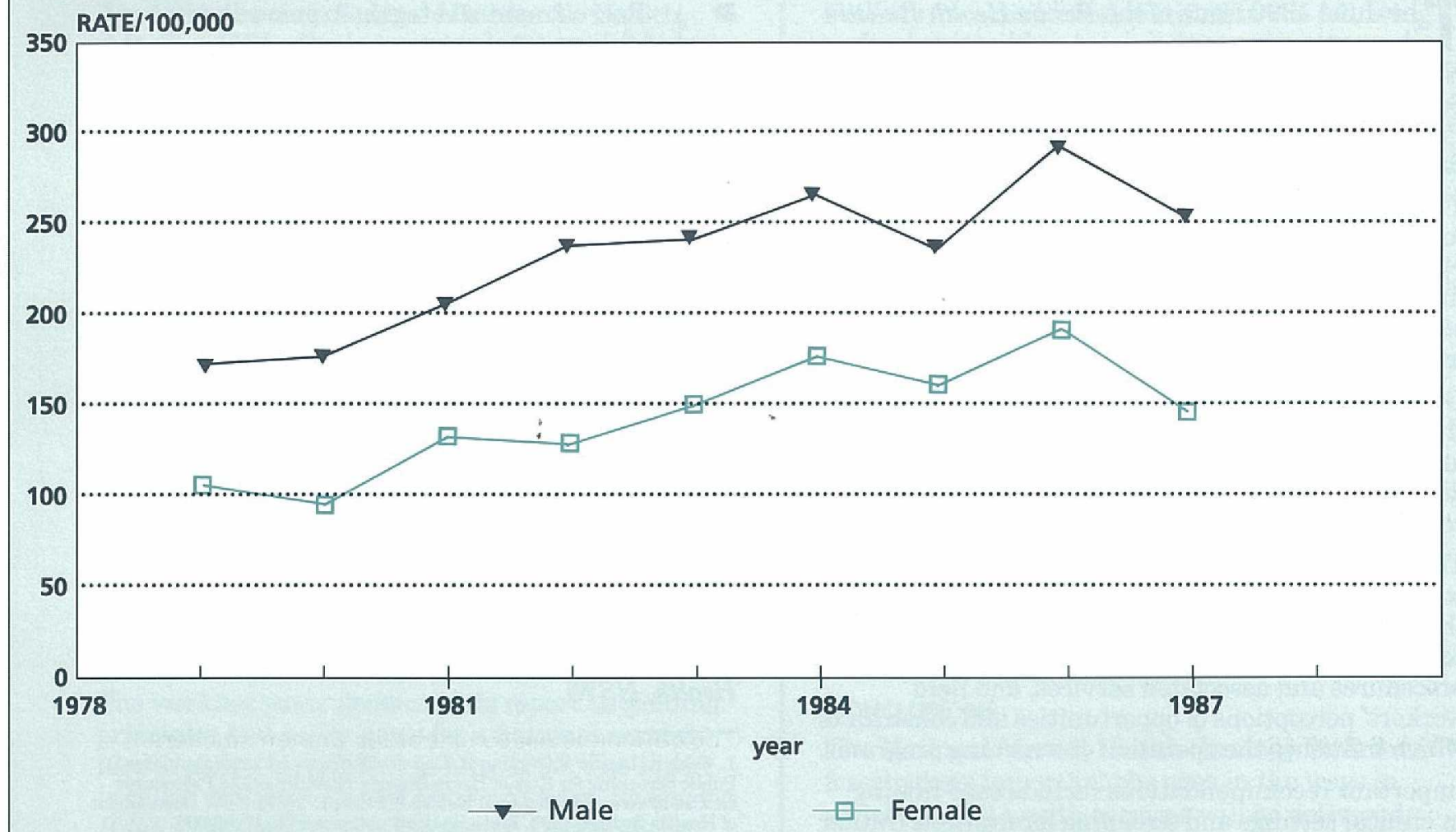

\section{FIGURE 4}

LUNG CANCER DEATH, 1971-1987

45-64 YEARS
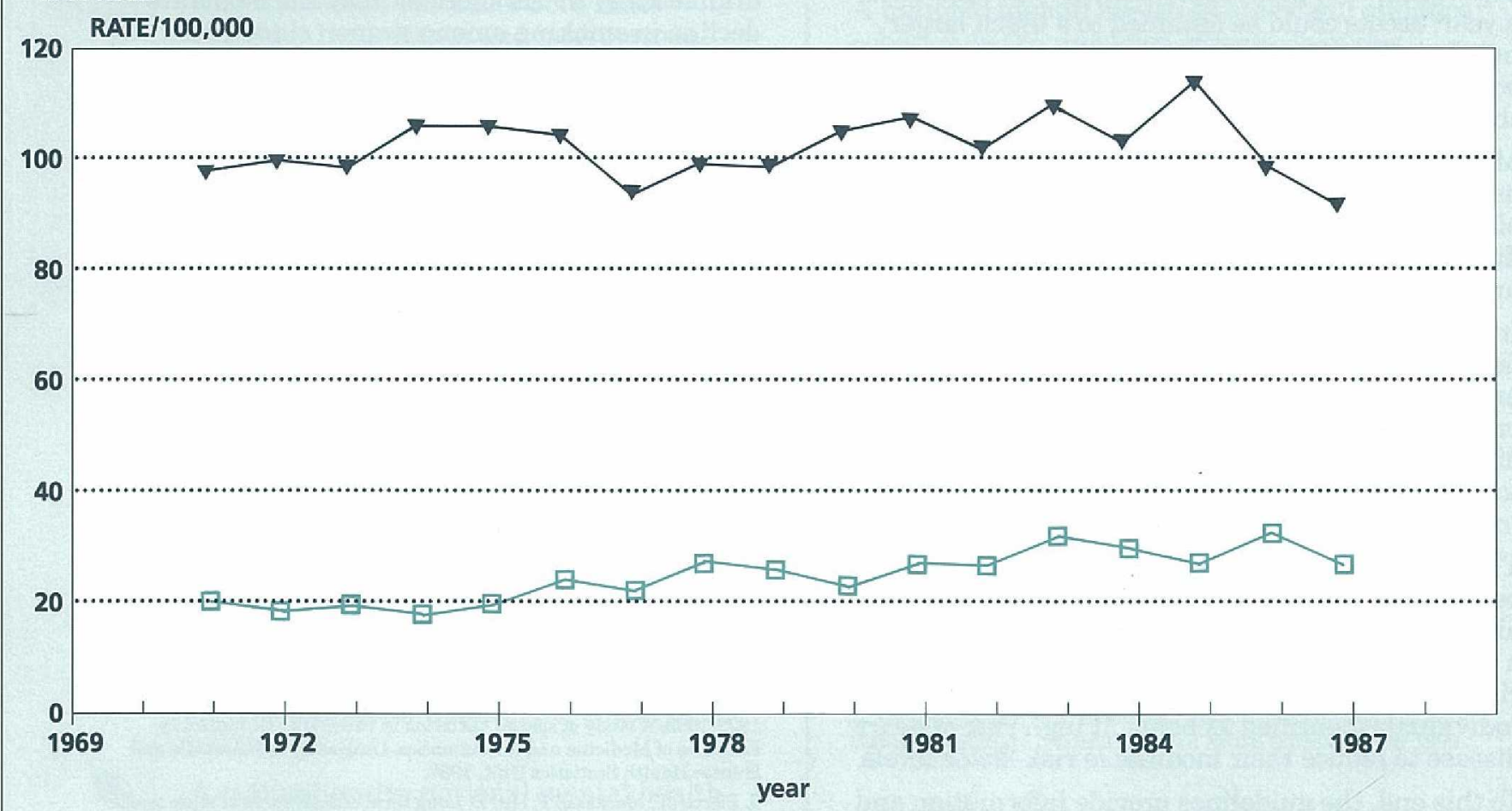

$$
\longrightarrow \text { Male } \quad \square \text { Female }
$$




\section{HeART DISEASE SCREENIN $\mathbf{G}$}

7 he he June 1990 issue of the Public Health Bulletin drew attention to the recent publication by the NSW Department of Health of the monograph, Public Screening for Risk of Heart Disease: Guidelines and Procedures for Use by Area and Regional Health Services in NSW (principal author: Karen Webb)1.

The guidelines are part of the department's response to the review of heart-disease prevention projects in NSW. The review identified that, with the increasing involvement of public-health agencies in risk factor screening, there was a need to standardise screening measurement and intervention procedures.

Guidelines for Statewide application help to ensure the public receives consistent and accurate advice and appropriate intervention, and that heartdisease risk-factor monitoring is accurate and consistent, both within NSW and nationally.

The guidelines are based on information from several sources. These include relevant policies from the USA, the UK and Australia, expert opinion, contemporary scientific knowledge of sound public screening procedures and associated services, and field workers' perceptions of opportunities and constraints which influence the operation of screening programs. Important recommendations include case-finding in clinical settings and screening for multiple (rather than single) risk factors. In the case-finding approach, diagnosis and monitoring of treatment requirements and behavioural change can occur in a clinical setting. One of the prime reasons for suggesting the case-finding approach is that 75-80 per cent of the population visit general practitioners at least once a year; access could be obtained to a much larger number of people through general practitioners and occupational health services than would be possible through public screening.

Modifiable risk factors recommended for assessment include elevated serum cholesterol, elevated blood pressure, smoking, excess total dietary fat, saturated fat and cholesterol, obesity, and low levels of physical activity.

Information on the following non-modifiable risk factors should also be obtained: age, sex, occupation and education, ethnicity/Aboriginality, and a personal or family history of premature heart disease and/or diabetes mellitus. This information can be used to identify higher-risk groups, plan tailored interventions and motivate behaviour modification.

The guidelines emphasise that screening should be designed and conducted primarily as a strategy aimed at detecting people with elevated risk, not as a whole-population strategy (aimed at lowering the risk of the whole population). Screening should lead individuals identified as being at high risk of heart disease to reduce their modifiable risk-factor levels. To this end, the guidelines provide information and recommended procedures on the following essential components of risk-factor screening programs:
- Recruitment strategies to ensure or improve utilisation of programs by the high-risk population.

- Risk-factor measurement and assessment methods and feedback procedures.

The intervention components of screening content and process guidelines.

Procedures for referral to appropriate community and medical services for further assistance with risk reduction.

Follow-up risk assessment to identify changes, encourage maintenance of positive change, and supply further intervention and referral for those who have not made positive changes.

Monitoring of the utilisation of a screening program and change in risk status of highrisk participants.

Denise Adams

Hazardous Substances Unit, WorkCover Authority (formerly Health Promotion Unit, Department of Health, NSW) 1. Webb K, Leeder S, Tupling H, Calvert D, Brown I, Carter B, Adams D. Public Screening for Risk of Heart Disease. Guidelines and Procedures of Health, Sydney, 1990. State Health Publication No HP89/096.

We should see the lung cancer rates in women continue to rise, a trend not likely to be altered dramatically in the short term by the moderate decline in smoking among women since 1983.

SC Fung, $M$ Rob, $D$ Lyle, G Rubin

Epidemiology and Health Services Evaluation Branch, NSW Department of Health.

Acknowledgements

The authors thank Mr Paul Lam, Hunter Health Statistics Unit, for providing standardised NSW mortality unit record data for 1971-88.

\section{EDITORIAL COMMENT}

These three examples highlight how information contained in the mortality report can be used to: 1) focus attention on leading age-sex-specific causes of death, 2) take note of causes of death where there have been static or increasing trends, and 3) focus research and public health action.

The NSW Department of Health has made study of SIDS one of its public health priorities. Accordingly, a Statewide SIDS surveillance system is being established.

1. Health For All Australians. Report of the Health Targets and Implementation Committee. AGPS, Canberra, 1988.

2. O'Connell DL, Lam P, Gibberd RW. Mortality in New South Wales 1979-1983, A study of spatial variation in cause-specific mortality. Faculties of Medicine and Mathematics, University of Newcastle and Hunter Health Statistics Unit, 1987.

3. Pierce JP, Macaskill P, Hill D. Long term effectiveness of mass medialed anti-smoking campaigns in Australia. Am J Pub Health 1990, 80, 565-569.

4. Department of Health, NSW Quit For Life, 1990 Community and Workplace Resource Manual. 